\title{
Jaringan Sosial (Social Network) Antar Jantan Monyet Ekor Panjang (Macaca fascicularis) Di Gunung Meru, Padang, Sumatera Barat
}

\section{The Social Network Between Male Long - Tailed Maqaques (Macaca fascicularis) at Gunung Meru, Padang, West Sumatera}

\author{
Ami Hidayat*, Rizaldi ,Jabang Nurdin \\ Laboratorium Ekologi Hewan Jurusan Biologi FMIPA Universitas Andalas \\ *Koresponden: amihidayatsyah@gmail.com
}

\begin{abstract}
A study on social network based on grooming interactions among males of long-tailed macaques (Macaca fascicularis) at Gunung Meru, Padang has been conducted from August to October 2015. The dominance relationship determined by submissive interactions among 17 adult males. Submissive interactions were recorded using ad libitum observation and grooming interactions by continuous recording method. The results showed that the dominance hierarchy among males was linear (Matman linearity index: $h^{\prime}=0.97$ ). Alfa male appeared to have the highest centrality index among all the males. This study indicates that individuals attained higher dominance hierarchy tend to have higher degree of centrality.
\end{abstract}

Keywords : centrality, dominance hierarchy, grooming, social network, submissive,

\section{Pendahuluan}

Monyet ekor panjang (Macaca fascicularis) adalah salah satu jenis satwa liar yang mampu hidup diberbagai tipe habitat. Di Indonesia monyet ekor panjang ini dapat ditemukan mulai dari pulau Sumatera hingga Sulawesi (Van der Zon, 1979). Jenis monyet ini tidak hanya hidup di dekat wilayah garis pantai tetapi juga didalam hutan bahkan terdapat juga kelompok yang hidup di dekat pemukiman warga (Roonwal dan Monhot, 1977).

Monyet ekor panjang hidup berkelompok. Setiap individu dalam kelompok berinteraksi satu sama lain. Interaksi tersebut terdiri atas berbagai tingkah laku sosial, diantaranya tingkah laku grooming, agonistic, bermain dan seksual (Septiana, 1996). Interaksi yang dilakukan secara berulang ulang oleh masing-masing jantan dewasa menunjukkan hubungan antar sesama individu yang pada gilirannya dapat diketahui hubungan satu sama lain berapa jaringan sosialnya (social network) (Wasserman dan Faust, 1994). Analisis jaringan sosial juga diterapkan untuk melihat kedekatan hubungan antara individu yang satu dengan individu lainnya (Voelkl dan Kasper, 2009).

Di Gunung Meru ditemukan sebanyak 17 jantan dewasa 15 betina dewasa, 18 jantan remaja, 10 betina remaja, 18 anak anak dan 8 bayi (Ilham, 2016). Jumlah individu jantan dalam kelompok ini sangat banyak dibandingkan dengan kondisi biasa. Kelompok ini juga telah terhabituasi dengan kedatangan manusia yang sering memberikan makanan (Bercovitch dan Huffman, 1999).

Jumlah pengunjung Gunung Meru cukup tinggi, banyak pengunjung yang memberikan makanan kepada kelompok 
monyet ekor panjang yang berada di daerah gunung meru, seperti kacang dan buah (Ilham, 2016)

Jumlah jantan yang tidak wajar didalam kelompok dan bentuk dari hubungan antar jantan dewasa yang belum diketahui maka dilakukanlah penelitian tentang jaringan sosial mereka.

\section{Metode Penelitian}

Penelitian ini dilaksanakan dari bulan Agustus sampai dengan bulan Oktober 2015 didaerah Gunung Meru, Kelurahan Teluk Nibung, Kecamatan Lubug Begalung, Kota Padang, provinsi Sumatera
Barat. Gunung Meru masuk kedalam wilayah administratif Kota Padang, yang berjarak lebih kurang $8 \mathrm{~km}$ dari pusat Kota Padang. Daerah Gunung Meru ini merupakan bukit batu yang berada di pinggir pantai dengan ketinggian $152 \mathrm{mdpl}$. Penelitian ini dilakukan terhadap kelompok Calak yang sering terlihat dibagian lereng bukit hingga ke jalan umum yang banyak dilalui kendaraan dan warga.

Kondisi habitat Gunung Meru yang menjadi tempat hidup bagi Macaca fascicularis ini sebagian telah menjadi perladangan dan pemukiman peduduk serta

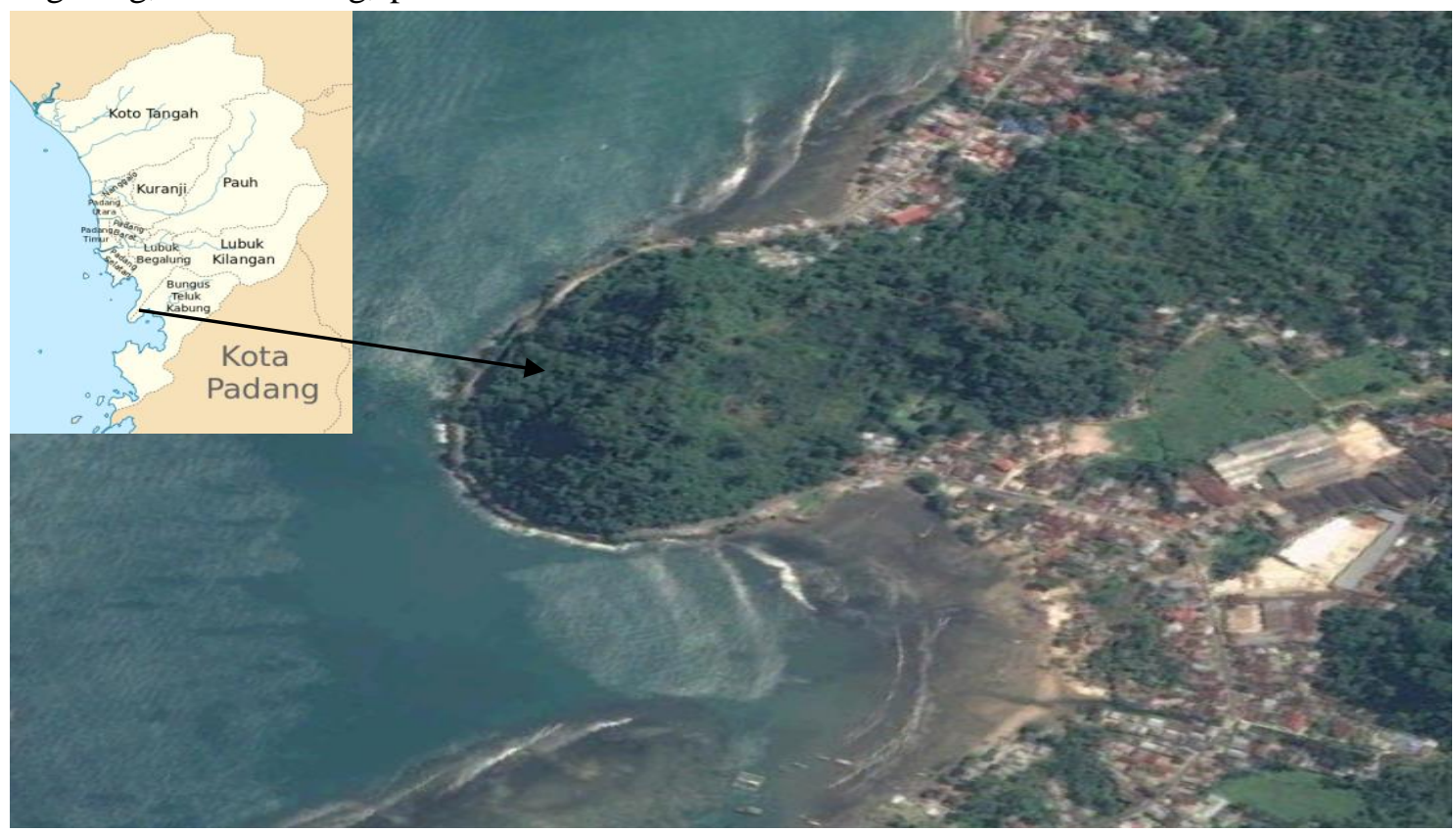

Gambar 1. Lokasi pengamatan di Gunung Meru (Sumber: Google earth, 2017)

dijadikan objek wisata oleh masyarakat setempat. Penelitian ini dilakukan kepada kelompok Calak yang hidup didaerah Gunung Meru terdiri dari 17 jantan dewasa, 15 betina dewasa, 18 remaja jantan, 10 remaja betina, 18 anak anak dan 8 bayi. Penelitian difokuskan pada 17 individu jantan dewasa monyet ekor panjang sebagai hewan fokal. individu yang telah diidentifikasi diberi nama secara sistematik yaitu dengan cara mengamati ciri-ciri khusus dan tempat-tempat yang sering dikunjungi oleh setiap individu untuk mempermudah setiap pengamatan. Pencatatan data tingkah laku dilakukan antara pukul 06.00 hingga 18.00 WIB. Tabel sociomatrik diolah dengan menggunakan software MATMAN 1.0 untuk menentukan dominansi hirarki dan uji Spearman rank correlation test. Kemudian sociogram digambarkan dengan menggunakan aplikasi Sociogram. Alat yang digunakan dalam penelitian ini adalah, kamera, alat tulis, teropong dan stopwatch. 
Tingkah laku yang diamati terhadap individu jantan berupa tingkah laku submissive dan grooming. Tingkah laku submissive dicatat dengan metode ad libitum dengan mencatat yang dilakukan oleh individu yang diamati secara tidak sistematis dan acak, sementara itu pencatatan data tingkah laku grooming antar individu menggunakan metode Continous recording (Altman, 1974) dengan membagi pengamatan menjadi beberapa sesi, selama 20 menit untuk masing-masing sesi (Rizaldi dan Watanabe 2010).

\section{Hasil dan Pembahasan}

Tabel 1. Total frekuensi submissive, grooming dan durasi grooming serta jumlah pasangan grooming

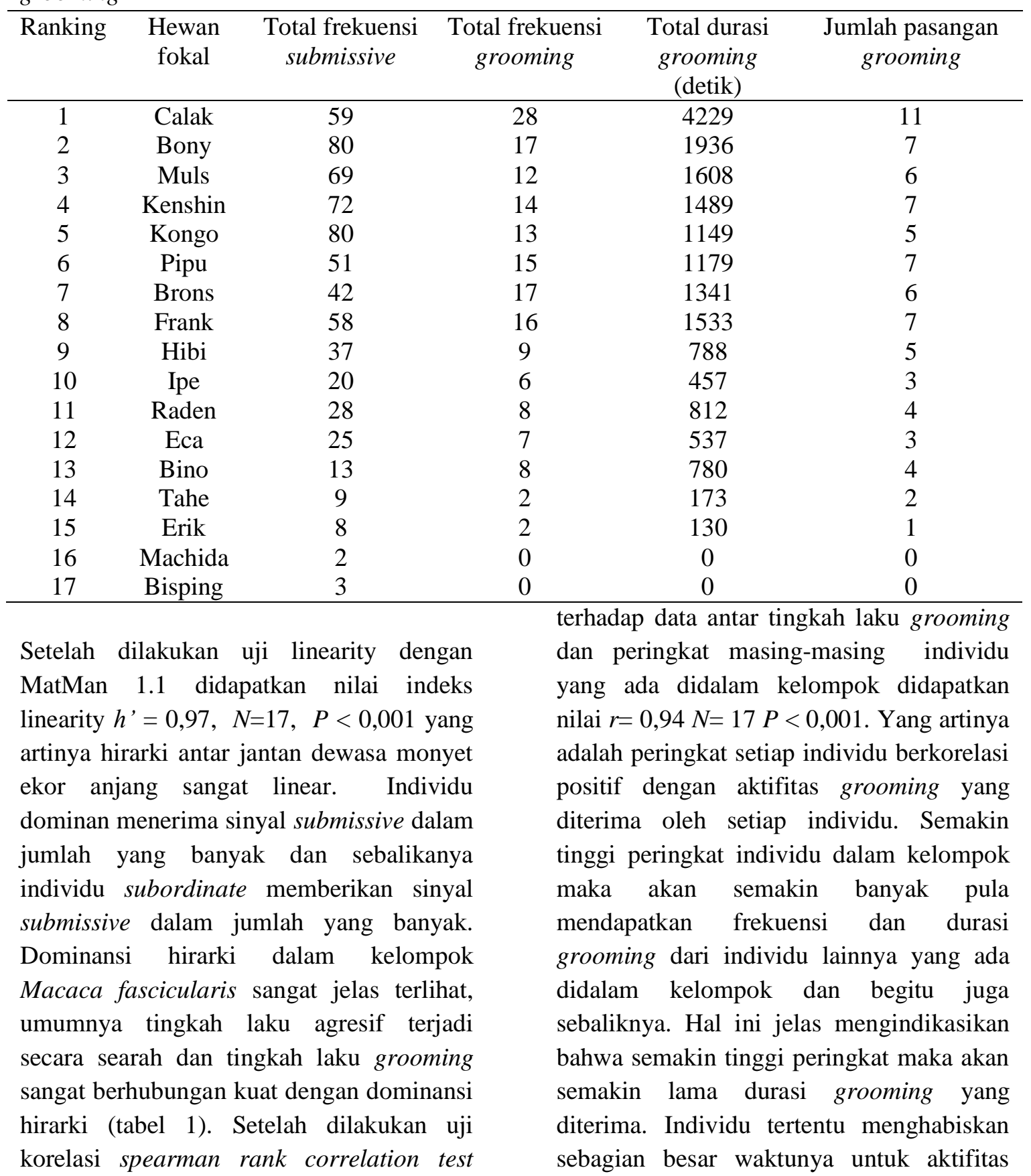


grooming. Durasi grooming dipengaruhi oleh linearitas hubungan antar individu, dimana makin dekat hubungan sosial antar indvidu maka semakin lama durasi grooming dilakukan (Schino, 2001).

Grooming yang telah dilakukan oleh individu subordinate dapat mengurangi stres dan membentuk hubungan yang baik dengan individu yang dominan serta mempermudah individu subordinate dalam mengakses sumber daya makanan yang ada (Barret dan Henzi, 1999). Meskipun hubungan antar dominansi dan grooming sering ditemukan signifikan namun dominansi bukanlah satu-satunya hal yang dapat menentukan terjadinya grooming. Kekerabatan atau hubungan keluarga juga bisa menjadi salah satu hal yang mempengaruhi terjadinya grooming (Loy dan Harnois (1998). Berdasarkan data interaksi grooming maka dihitung derajat sentralitasnya masing-masing individu (tabel2)

Tabel 2 . Derajat sentralitas masing-masing individu

\begin{tabular}{cc}
\hline Individu fokal & Derajat sentralitas \\
\hline Calak & 0,68 \\
Bony & 0,43 \\
Muls & 0,37 \\
Kenshin & 0,43 \\
Kongo & 0,31 \\
Pipu & 0,43 \\
Brons & 0,37 \\
Frank & 0,43 \\
Hibi & 0,31 \\
Ipe & 0,18 \\
Raden & 0,25 \\
Eca & 0,18 \\
Bino & 0,25 \\
Tahe & 0,12 \\
Erik & 0,06 \\
Machida & 0,00 \\
Bisping & 0,00 \\
\hline
\end{tabular}

Setelah dilakuan uji korelasi antara dominan hirarki dan sentralitas didapatkan korelasi positif yang kuat, semakin tinggi peringkat individu dalam kelompoknya maka akan semakin banyak dan lama individu tersebut berinteraksi dengan individu lain $(r=0,91 \mathrm{~N}=17 \mathrm{P}<0,001)$. Calak sebagai individu dominan memiliki sentralitas yang paling tinggi dibandingkan anggota kelompok lainnya. Jantan yang belum dewasa mewarisi peringkat induk mereka selama kehidupan mereka masih bergantung kepada induknya (kawamura 1958). Ukuran sentralitas ini menunjukkan pentingnya keberadaan individu tertentu didalam kelompoknya dan kedekatan hubungan antar masing-masing individu didalam kelompok. ketika individu dengan sentralitas yang tertinggi dihilangkan didalam jaringan, jumlah jaringan menurun drastis. Temuan ini menunjukkan bahwa individu dengan sentralitas yang tinggi memainkan peran penting dalam menjaga hubungan jaringan (patricia, 2011) 


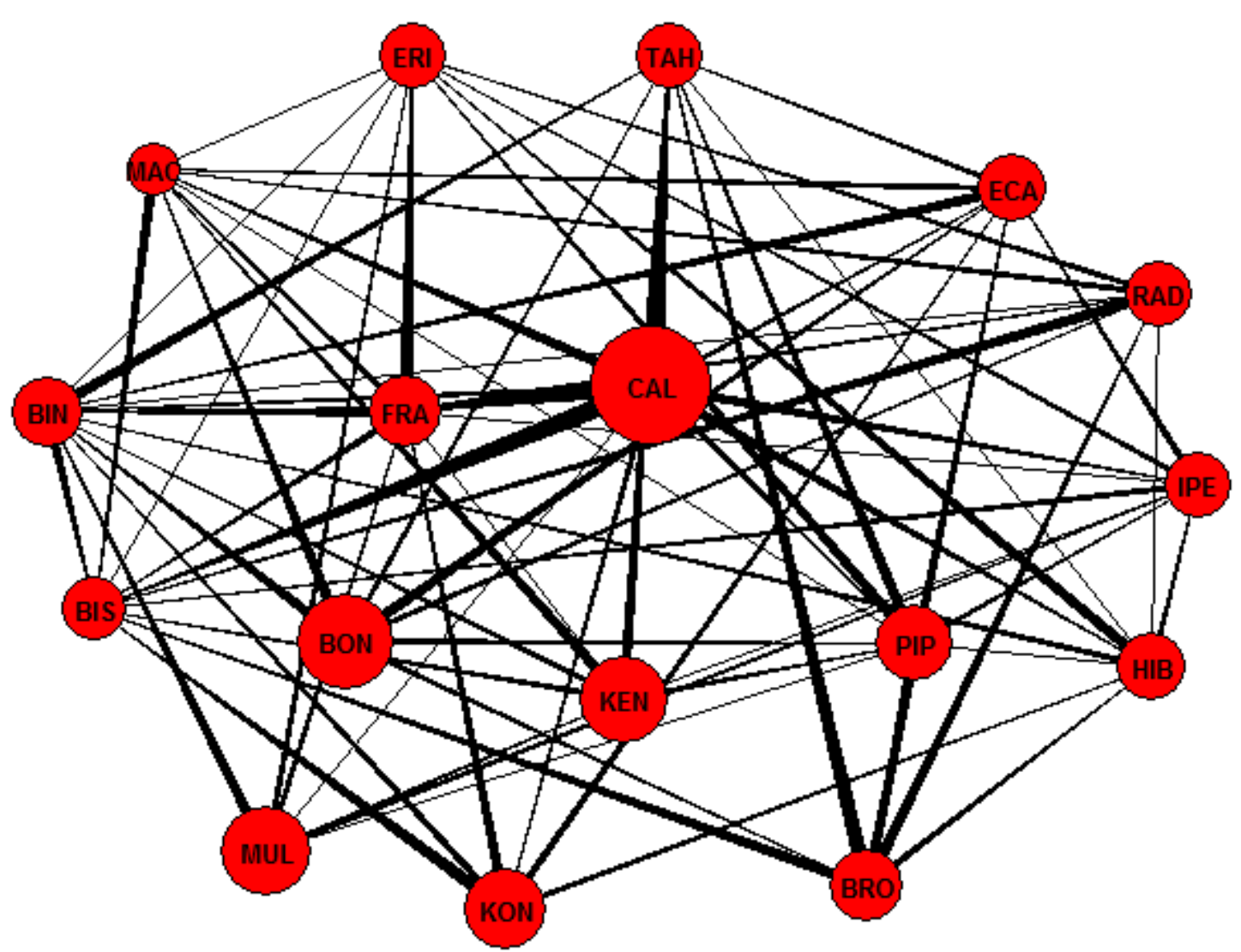

Gambar2. Sociogram antar jantan dewasa dalam kelmpok monyet ekor panjang di Gunung Meru. Masing-masing lingkaran merepresentasikan satu individu focal dan ukuran dari lingkaran merepresentasikan sentralitas individu

Machida dan Bisping sebagai individu dengan peringkat terendah didalam kelompok dengan nilai sentralitas paling rendah atau dapat dikatakan tidak memiliki nilai sentralitas sama sekali. Hubungan antar individu dalam kelompok Macaca fascicularis disebut dengan hubungan yang despotik (dominansi individu yang sangat asimetris), yang menandakan bahwa dominansi hirarki dalam suatu kelompok sangatlah menentukan hubungan antar masing-masing individu (Aurelli,1997). Status sosial didalam kelompok akan sangat menentukan sentralitas individu didalam jaringan sosial kelompok tersebut. Dalam hal ini dapat dilihat bahwa individu jantan dewasa Macaca fascicularis dengan status sosial paling tinggi yaitu Calak memiliki sentralitas yang sangat tinggi dalam jaringan sosial kelompoknya (gambar 2). Hal ini terjadi karena tipe hubungan mereka yang despotik, dimana individu yang paling dominan akan menguasai seluruh sumber daya yang ada seperti makanan ataupun akses terhadap betina (Takahashi dan Furuichi, 1998). Calak sebagai individu yang memiliki sentralitas paling tinggi didalam jaringan sosial kelompoknya juga sangat memungkinkan memberikan dampak yang buruk pada kelompoknya, seperti penyebaran penyakit ataupun parasit (Griffin dan Charles, 2012). Dimana hampir seluruh individu yang ada didalam kelompok berhubungan dengannya maka dapat dipastikan setiap individu yang berhubungan tersebut akan terkena penyakit 
juga. Menurut (Newman, 2005) Individu dengan sentralitas yang tinggi juga memiliki kontrol terhadap informasi antara satu sama lain dalam kelompok.

\section{Kesimpulan}

Dominansi hirarki jantan dewasa monyet ekor panjang (Macaca fascicularis) di Gunung Meru Padang adalah linear $(h=$ 0,97). Peringkat setiap individu berkorelasi positif dengan aktifitas grooming yang diterima oleh setiap individu. Semakin tinggi peringkat individu dalam kelompok maka akan semakin sering dan semakin lama pula mendapatkan grooming dari individu lainnyadan begitu juga sebaliknya. Jantan Alfa (Calak) merupakan individu sentral yang memiliki peranan paling kuat didalam jaringan sosial kelompoknya yaitu dengan nilai sentralitas 0,68 .

\section{Ucapan terima kasih}

Terima kasih kepada Kurnia Ilham dan Putriana Haragus yang telah banyak membantu dalam proses pelaksanaan penelitian ini dillapangan dan berbagi artikel terkait dengan penelitian ini.

\section{Daftar Pustaka}

Altmann, J. 1974. Observational Study of Behavior: Sampling Methods. University of Chicago. United State of America.

Aurelli. 1997. Differential kinship effect on reconciliation in three species of Macaques (Macacca fascicularis, M. fuscata, M. sylvanus). Journal of comparative psychology. Vol 111 (1). 91-99

Barrett, L and S. P. Henzi. 1999. Market Forces Predict Grooming Reciprocity in Female Baboons. Proceedings of the Royal Society London 266: 665-670.

Bercovitch, F. B. and M. A. Huffman 1999. The macaques. In the nonhuman primates. Dolhinow, $\mathrm{P}$ and $\mathrm{A}$. Fuentes (Ed.), Mayfield Publishing, California 112-120.
Griffin, H.R and Charles, L.N. 2012. Community structure and the pread of infectious disease in primate social networks. Evolutionary Ecology 26: 779-800

Ilham, K., Rizaldi., J.Nurdin, Y.Tsuji. 2016. Status of urban population of the male long - tailed macaque (Macaca fascicularis) in West Sumatera, Indonesia. Primates 58: 295-305

Kawamura, S. 1958. Matriarchal social ranks in the Minoo-B troop: A study of the rank system of Japanese monkeys. Primates 1: $148-156$

Lindburg, D.G. 1971. The Rhesus Monkey in North India: an Ecological and Behavioral Study. In: Rosenblum, L.A. (Eds). Primate behavior: developments in field laboratory research, vol. 2. Academic Press, New York. 1-106.

Loy, J and Harnois, M. 1988. An Assessment of Dominance and Kinship among Patas Monkeys: Primates 29: 331-342

Newman, M. 2005. A measure of betweenness centrality based on random walks. Social Network 27: 39-54

Patricia, K and Cedric, S. 2011 Grooming Network Cohesion and the Role of Individuals in a Captive Chimpanzee Group. American Journal of Primatology 73:758-767

Preuschoft, S and van Schaik, C. P. 2000. Dominance and Communication. Conflict Management in Various Social Settings. In: F. Aurelli and F.B.M de Waal (Eds). Natural Conflict Resolution. University of California Press. Berkley, California. 77-105

Rizaldi and K. Watanabe. 2010. Early development of peer dominance relationships in a captive group of japanese macaques Macaca fuscata.Current zoologi 56(2) : 190-197 
Roonwal, M. L. and S. M. Monhot. 1977. Primates of South Asia. Harvard University press. Cambridge.

Schino, G. 2001. Grooming, Competition and Social Rank among Female Primates: A meta-analysis. Animal Behaviour. 62: 265-271.

Septiana, A. 1996. Tingkah Laku Bermain Beruk (Macaca nemestrina) di Penangkaran Pusat Studi Satwa Primata (PSSP) Lembaga Penelitian IPB Darmaga. Skripsi Sarjana Biologi FMIPA Institut Pertanian Bogor. Bogor.

Takahashi, H. and T. Furuichi. 1998. Comparative Study of Grooming Relationships among Wild Japanese Macaques in Kinkazan A troop and Yakushima M troop. Primates 39: 365-374.

Van der Zon, A.P.M. 1979. Mammal of Indonesia. UNDP/FAO National Park Development Project. Bogor

Voelkl, B. And Kasper,C. 2009. A social network analysis of primate group. Primates 50: 343-356

Wasserman, S and K, Faust. 1994. Social Network Analysis: Methods and Applications. In: Granovetter M, (Eds). Structural Analysis in the Social Science. Cambridge University press. Cambridge. 825 